\title{
Uma leitura freireana sobre a BNC-Formação: a persistência no erro epistemológico do bancarismo
}

\author{
Ronaldo Antonio Gollo Júnior* \\ Elisabete Ferreira Esteves Campos**
}

\section{Resumo}

Neste ensaio, problematizamos a BNC-Formação, de caráter pragmatista, para o desenvolvimento de competências e habilidades nos cursos de licenciatura, revelando seu aspecto regulatório. Com o aporte teórico de Paulo Freire, o objetivo é abordar termos progressistas, como autonomia e criticidade, apropriados pelos grupos (neo)liberais-conservadores que participam da formulação de políticas educacionais, atribuindo a esses termos significados que se vinculam à lógica empresarial da educação. Conclui-se que a teoria de Paulo Freire contribui para o desvelamento de tais políticas, na medida em que pode ser compreendida pelas equipes de docentes universitários com vistas à reformulação do Projeto Pedagógico das licenciaturas em uma perspectiva contra-hegemônica.

Palavras-chave: Paulo Freire; BNC-Formação; formação de professores.

* Mestre em Educação pela Universidade Metodista de São Paulo. Licenciado em Matemática, com experiência em docência na educação básica. É membro do Grupo de Pesquisa Políticas de Gestão Educacional e de Formação dos Profissionais da Educação e do Grupo de Estudos Paulo Freire, da Universidade Metodista de São Paulo. E-mail: ronaldo.gollo@gmail.com

** Doutora em Educação pela Universidade de São Paulo-USP. Docente e pesquisadora no Programa de Pós-Graduação em Educação da Universidade Metodista de São Paulo. Líder do Grupo de Pesquisa Políticas de Gestão Educacional e de Formação dos Profissionais da Educação e do Grupo de Estudos Paulo Freire. E-mail: elisabete.campos@metodista.br 


\title{
A Freirean reading of the Brazilian Common Core: the persistence in the epistemological error of banking model of education
}

\begin{abstract}
In this essay, we problematize the pragmatist BNC-Training, of pragmatic character, for the development of competences and skills in undergraduate courses, revealing its regulatory character. With the theoretical contribution of Paulo Freire, the objective is to address progressive terms, such as autonomy and criticality, which were appropriated by (neo)liberal-conservative groups that participate in the formulation of educational policies, giving these terms meanings that are linked to the business logic of education. It is concluded that Paulo Freire's theory contributes to the unveiling of such policies, insofar as it can be understood by teams of university professors with a view to reformulating the Pedagogical Project of licentiate degrees in a counter-hegemonic perspective.
\end{abstract}

Keywords: Paulo Freire; BNC-Training; teachers training.

\section{Una lectura freireiana sobre la BNC-Formación: per- sistencia en el error epistemológico del bankismo}

\section{Resumen}

En este ensayo, problematizamos la BNC-Formación, de carácter pragmático, para el desarrollo de habilidades y destrezas en cursos de pregrado, revelando su aspecto regulatorio. Con el aporte teórico de Paulo Freire, el objetivo es abordar términos progresistas, como autonomía y criticidad, apropiados por los grupos (neo)liberales-conservadores que participan en la formulación de políticas educativas, atribuyendo a esos términos significados que están vinculados a la lógica empresarial de la educación. Se concluye que la teoría de Paulo Freire contribuye al desmantelamiento de tales políticas, en la medida en que puede ser entendida por los equipos de profesores universitarios con vistas a reformular el Proyecto Pedagógico de las licenciaturas en una perspectiva contrahegemónica.

Palabras clave: Paulo Freire; BNC-Formación; formación del profesorado. 


\section{Introdução}

As mais recentes Diretrizes Curriculares Nacionais - DCN - para a formação de professores, a Base Nacional Comum para a Formação Inicial de Professores da Educação Básica - BNC-Formação -, foram divulgadas por meio da Resolução $\mathrm{CNE} / \mathrm{CP} \mathrm{n}^{\circ} 2$, de 20 de dezembro de 2019, publicadas em 10 de fevereiro de 2020 e republicadas, com correções, em 15 de abril de 2020 (BRASIL, 2020). Além de revogar as DCN anteriores, fixadas pela Resolução $\mathrm{CNE} / \mathrm{CP}$ n $^{\circ} 2$, de 20 de dezembro de 2015, antes do prazo para sua implementação ter expirado, a BNC-Formação apresenta novas diretrizes que devem ser implementadas nos prazos estabelecidos pelo artigo 27:

Art. 27 - Fica fixado o prazo limite de até 2 (dois) anos, a partir da publicação desta Resolução, para a implantação, por parte das Instituições de Ensino Superior (IES), das Diretrizes Curriculares Nacionais para a Formação Inicial de Professores para a Educação Básica e da BNC-Formação, definidas e instituídas pela presente Resolução. Parágrafo único. As IES que já implementaram o previsto na Resolução CNE/CP n ${ }^{\circ} 2$, de $1^{\circ}$ de julho de 2015 , terão o prazo limite de 3 (três) anos, a partir da publicação desta Resolução, para adequação das competências profissionais docentes previstas nesta Resolução” (BRASIL, 2020, p. 12).

Analisando as DCN, identificamos a valorização da “[...] formação permanente para o exercício profissional [...]”, “[...] com liberdade, autonomia, consciência crítica e responsabilidade [...]" (BRASIL, 2020, p. 13), por meio de um discurso aparentemente progressista, mas assumindo, de forma contraditória, a epistemologia do desenvolvimento de competências formulada pelos "reformadores empresariais" (FREITAS, 2012) que participam da elaboração de políticas educacionais de cunho (neo)liberal, cujo caráter reacionário acentuou-se no atual Ministério da Educação, "conduzindo a uma sociedade individualista com as consequências já descritas por Giroux (2017)" (FREITAS, 2018, p. 59).

$\mathrm{Na}$ BNC-Formação, há a exigência de que os futuros e futuras docentes desenvolvam a competência para "compreensão dos 
contextos socioculturais dos estudantes e dos seus territórios educativos", para que dominem os objetos do conhecimento e saibam como ensiná-los (BRASIL, 2020, p. 7). Tais objetos de conhecimento, no entanto, são definidos na BNCC para a educação básica (BRASIL, 2017), que instituiu uma política de regulação por meio de uma lista de competências e habilidades que desconsidera a realidade diversa de nosso país.

Direcionar os cursos de licenciatura para que sejam o início de uma formação permanente, com o discurso do desenvolvimento da autonomia, da consciência crítica e respeitando o contexto dos e das estudantes, são pressupostos que podem levar a uma errônea compreensão de que a BNC-Formação se ampara em conceitos da filosofia educacional de Paulo Freire, que com sua vida e obra nos ensinou que o processo educativo é permanente, visando ao desenvolvimento da autonomia, a partir dos saberes de experiências cotidianas dos educandos (FREIRE, 1981, 2008, 2019).

Distante da pedagogia freireana, a BNC-Formação aproxima-se de um modelo de educação bancária criticada por Freire (2019), com base em uma concepção formativa aplicacionista, como consta no artigo 15, parágrafo $3^{\circ}$ da Resolução, no qual "a prática [de estágio] deverá ser engajada e incluir a mobilização, a integração e a aplicação do que foi aprendido no curso" (BRASIL, 2020, p. 9).

De acordo com o artigo 15, parágrafo $4^{\circ}$, “as práticas devem ser registradas em portfólio, que compile evidências das aprendizagens do licenciando requeridas para a docência, tais como planejamento, avaliação e conhecimento do conteúdo" (BRASIL, 2020, p. 9). A compreensão da avaliação do processo formativo organizando um compilado de evidências, supondo que os futuros professores e professoras apliquem o que aprenderam é, sem dúvida, uma proposta de formação transmissiva, bancária.

Partindo da crítica a esse modelo formativo, o presente ensaio pretende analisar as contribuições de Paulo Freire para a construção de outra perspectiva formativa que promova o desenvolvimento da consciência crítica dos docentes. 


\section{A filosofia educacional de Paulo Freire e as contri- buições para a formação de professores}

A despeito de Paulo Freire não ter escrito especificamente sobre cursos de formação de professores/as, sua experiência frente à Secretaria de Educação do Município de São Paulo (1989-1992) constitui-se em exemplo de construção participativa do processo formativo, e na extensa publicação do patrono da educação brasileira encontram-se fundamentos para a educação permanente, com base no conceito antropológico de sujeito inacabado.

Aliás, não seria freireano formular currículos prescritivos para as licenciaturas e formações em serviço de docentes. Temos, em Freire (2001a), a compreensão do currículo elaborado em comunhão, visando à elaboração da práxis docente, sendo o currículo uma obra em construção no contexto da realidade em que incide.

Um currículo fundamentado na pedagogia de Paulo Freire, como afirmou Gadotti (2002, p. 8), "é um convite para transformar o mundo", uma vez que o ato educativo abriga a possibilidade de ser práxis, ou seja, de ser uma "ação dos homens sobre o mundo para transformá-lo” (FREIRE, 2019, p. 52).

O conceito de práxis, em Freire (1981, 1997, 2019), parte da epistemologia dialética-dialógica onde as ideias, as culturas ${ }^{1}$ e os saberes são compreendidos como sendo produzidos pelo acúmulo do trabalho de todas as gerações humanas que nos antecederam. Nesse sentido, os seres humanos são "seres que, transformando o mundo com seu trabalho, criam seu mundo. Este mundo, criado pela transformação do mundo que não criaram e que constitui seu domínio, é o mundo da cultura que se alonga no mundo da história" (FREIRE, 1981, p. 17).

Considerando que as ideias, as teorias e as explicações da realidade são produzidas pelos seres humanos, a práxis, como

O termo cultura, em Paulo Freire, refere-se ao conceito antropológico que, como bem definiu Laraia (2001, p. 25) é "todo complexo que inclui conhecimentos, crenças, arte, moral, leis, costumes ou qualquer outra capacidade ou hábitos adquiridos pelo homem como membro de uma sociedade". 
ação transformadora, é a criadora do devir histórico, ou seja, a indissociabilidade entre ação e reflexão transformará a realidade em um movimento contínuo de mudança. Dessa forma, práxis é ação-reflexão-ação, a unidade dialética entre teoria e prática, entre trabalho corporal e trabalho intelectual, entre subjetividade e objetividade, em que ambos se superam pelas suas contradições e contraposições (FREIRE, 1981, 1997, 2019).

Toda ação humana é direcionada, porém, ela somente é práxis caso exista a reflexão que leve ao conhecimento sobre sua finalidade, "sem o que não seria práxis, ainda que fosse orientação no mundo. E não sendo práxis seria ação que ignoraria seu próprio processo e seus objetivos" (FREIRE, 1981, p. 35). Foi nesse sentido que Freire $(1997,2008,2019)$ afirmou que todo ato educativo é um ato político, pois, não somente a educação, mas todas as ações dos seres humanos sobre o mundo, implicam direcionamentos para a sociedade e para os indivíduos. Independentemente da consciência dos sujeitos sobre a diretividade de suas ações, ainda assim ela é uma ação política.

Entre todos os seres vivos da natureza, os únicos capazes de exercerem a práxis são os seres humanos. Formigas, abelhas, pássaros, entre outros, também trabalham e possuem diretividade em suas ações, porém, somente os seres humanos são capazes de refletir e optar pela sua diretividade. A reflexão transformou-os em seres de escolha, fazendo com que não seja possível fugir das questões éticas que a consciência lhes impõe, resultando em constantes transformações da realidade. Porém, "é pouco provável conseguir a criticidade dos educandos" quando a educação é "domesticadora" (FREIRE, 2001b, p. 37).

Assim, surge a condição humana de educação permanente, pela práxis, pois, refletindo sobre as ações, sobre as transformações realizadas pelo trabalho humano, os seres humanos compreenderam-se inacabados, em constante transformação, inseridos em um permanente processo esperançoso na busca por ser mais. Essa é, conforme Freire (2008, 2011, 2019), a vocação ontológica do ser humano.

É neste sentido que só falo em subjetividade entre seres que, inacabados, 
se tornaram capazes de saber-se inacabados, entre os seres que se fizeram aptos de ir mais além da determinação, reduzida, assim, a condicionamento e que, assumindo-se como objetos, porque condicionados, puderam arriscar-se como sujeitos, porque não determinados (FREIRE, 2000, p. 27).

Apesar de condicionados pela realidade em que vivemos, não estamos determinados a ela, porém, essa realidade, conforme Freire (2019, p. 52), "é funcionalmente domesticadora", de forma que libertar-se somente é possível por meio de uma práxis autêntica. Abrigando um discurso de "morte da História que significa, em última análise, a morte da utopia e do sonho" (FREIRE, 2008, p. 59), a ideologia presente em nosso tempo inverte a realidade e faz com que as ideias passem a ser compreendidas como se fossem independentes das ações dos seres humanos, buscando assujeitar, desumanizar e domesticar os sujeitos como objetos de uma história que não pode se mover, tampouco se transformar pela ação humana.

O conceito de autonomia, em Freire (1981, 2008, 2011, 2019), está ligado à ideia de liberdade para ser mais, enquanto o conceito de heteronomia diz respeito aos seus impedimentos, ou seja, à domesticação sob a leitura de mundo realizada por terceiros. Um ser autônomo, pela práxis, faz e refaz a história e a si mesmo, pois na ação-reflexão-ação desenvolve a consciência crítica e com ela manifesta a esperançosa busca de ser mais, passando a agir como sujeitos, não mais como objetos, transformando a si e ao seu entorno. A consciência crítica, conforme Freire (2011), é a raiz da democracia, pois é a partir dela que a autonomia se constrói e, junto dela, a possibilidade de agir politicamente, pois conduz os seres humanos à compreensão de sujeitos inacabados e historicamente condicionados.

A consciência crítica é a representação das coisas e dos fatos como se dão na existência empírica. Nas suas correlações causais e circunstanciais. A consciência ingênua (pelo contrário) se crê superior aos fatos, dominando-os de fora e, por isso, se julga livre para entendê-los conforme melhor lhe agradar (FREIRE, 2011, p. 138). 
Quando bebês, os seres humanos adentram às sociedades e às culturas por meio da linguagem e pelas leituras de mundo realizadas por outrem, de forma que as primeiras ações estão condicionadas pelas relações espaço-temporais em que tais ocorrências se dão. Porém, a consciência crítica e as ações transformadoras, conforme Freire (2019, p. 114), são os fundamentos necessários para que tal condicionamento não se converta em determinismo, e essas são desenvolvidas com o diálogo, no encontro dos seres humanos para pronunciarem o mundo. "O diálogo é o encontro dos homens para Ser Mais", pois não há nenhuma realidade mais concreta que os seres humanos no mundo e com o mundo.

Como bem explicou Fiori, no prefácio de Pedagogia do Oprimido (FREIRE, 2019, p. 22), “os dialogantes 'admiram' um mesmo mundo; afastam-se dele e com ele coincidem; nele põem-se e opõem-se. Vimos que, assim, a consciência se existencia e busca perfazer-se. O diálogo não é um produto histórico, é a própria historicização". É nesse sentido que Freire (2008, 2019) afirma ser o diálogo um saber necessário à prática educativa. Não qualquer diálogo, mas um que, partindo dos saberes de experiências cotidianas dos educandos, proporcione "as condições em que se dê a superação do conhecimento no nível da 'doxa' pelo verdadeiro conhecimento, o que se dá, no nível do "logos”" (FREIRE, 2019, p. 97) e, assim, convertam-se em práxis na vida do educando e na consequente historicização dos fenômenos.

A oposição entre educadores/as bancários/as e educadores/ as problematizadores/as, apontada por Freire (1981, 2019), diz respeito a posições divergentes sobre a diretividade política da prática docente. Enquanto na ação bancária, os professores e professoras, considerados detentores do objeto de conhecimento que deve ser transmitido aos discentes, pronunciam e apresentam o mundo sob o qual os alunos e alunas se tornam objetos, os docentes problematizadores reconhecem que o educando e a educanda também são sujeitos, constituídos em uma perspectiva histórica e cultural. Assim, Freire $(1981,2008,2019)$ afirma que a problematização é 
uma escolha ética a ser realizada: ensinar os conteúdos programáticos de forma a objetificar os educandos na realidade pronunciada por terceiros, na distorção do ser mais, ou, então, problematizar os conteúdos programáticos a fim de que os educandos pronunciem a sua realidade pela práxis, na ação-reflexão-ação.

E por isso, conforme Freire (2001b, p. 37), é necessário que todos os profissionais da educação assumam a politicidade de suas profissões. "Não basta dizer que a educação é um ato político, assim como não basta dizer que o ato político é também educativo. É preciso assumir realmente a politicidade da educação”. A impossibilidade sobre a neutralidade na educação demanda uma escolha ética entre o bancarismo e a problematização, tanto na educação básica, quanto nos cursos de formação de professores. A formação docente pode basear-se no modelo bancário ou, ao contrário, contribuir para a consciência crítica, cujos saberes necessários não são tácitos e podem ser aprendidos, ou seja, não são adquiridos nas experiências cotidianas, embora possam ser consideradas como ponto de partida.

A educação crítica, problematizadora, é precisamente ética, pois, conforme Freire (2001b, p. 46), "a consciência do mundo, que me possibilita apreender a realidade objetiva, se alonga em consciência moral do mundo, com que valoro ou desvaloro as práticas realizadas no mundo contra a vocação ontológica dos seres humanos ou em seu favor". Aplicar uma educação bancária, com "sua concepção autoritária” (FREIRE, 2008, p. 14), é retirar a possibilidade da construção da autonomia. A desumanização dos sujeitos, inerente à prática bancária, impossibilita os seres humanos de seguir as suas vocações ontológicas, freando o devir histórico. Optar pelo educador problematizador é possibilitar o desenvolvimento da autonomia, respeitando a vocação ontológica de ser mais. "A opção, por isso, teria de ser também, entre uma 'educação' para a 'domesticação', para a alienação, e uma educação para a liberdade. 'Educação' para o homem-objeto ou educação para o homem-sujeito" (FREIRE, 2011, p. 43). 
Ainda que Paulo Freire, no final de sua vida, tenha escrito o livro Pedagogia da Autonomia, que abriga os "saberes necessários à prática educativa" (FREIRE, 2008), a demanda freireana para os cursos de formação de professores vão além de saberes e práticas docentes, pois também exige a conscientização docente, o respeito para o diálogo, a consciência crítica sobre o inacabamento da vida e da vocação ontológica de ser mais, que não se constituem "através de um trabalho intelectualista, mas na práxis - ação e reflexão" (FREIRE, 1981, p. 67). Posto isso, vale a pena observar os pressupostos apresentados pela BNC-Formação, bem como sobre a situação histórico-política em que foi concebida, para lançar luz sobre os pressupostos presentes nessa proposta, evidenciando as intencionalidades de tal política.

\section{$\mathrm{O}$ avanço do neoliberalismo e a BNC-Formação}

O neoliberalismo teve origem com o livro $O$ caminho da servidão, de Friedrich Hayek, originalmente publicado em 1944, mas foi após a crise do petróleo de 1973 e o consequente enfraquecimento econômico das elites que essa doutrina passou a ser implementada como política pública. Organismos internacionais orientaram os governos a "manter um Estado forte, sim, em sua capacidade de romper o poder dos sindicatos e no controle do dinheiro, mas parco em todos os gastos sociais e nas intervenções econômicas" (ANDERSON, 1995, p. 11). Atualmente, órgãos como a OCDE e o Banco Mundial buscam efetivar tais medidas.

Desde os anos de 1970, a educação brasileira, incluindo os cursos de formação de professores e professoras, vem sendo duramente impactada pelos direcionamentos das políticas neoliberais, que buscam a privatização dos principais setores de serviços públicos, como a educação e a saúde, e propõe uma formação educacional técnica, voltada ao mercado de trabalho. A Lei de Diretrizes e Bases da Educação Nacional - LDB - no 5.692, de 1971, apresentou pela primeira vez uma proposta com esse direcionamento, e a Lei $\mathrm{n}^{\circ}$ 9.394, de 20 de dezembro de 1996, a LDB mais recente, levou 
adiante esse projeto permitindo a transferência de dinheiro público para a educação privada (KUENZER, 1997).

As reformas educacionais implementadas pelos governos militares mudaram drasticamente a configuração da educação nacional. A busca pela universalização do ensino para jovens dos 7 aos 14 anos, proposta pela LDB de 1971, fez com que, no período de 1970 e 1980, dobrasse o número de matrículas e fossem criados " 52.891 estabelecimentos de ensino" (SOUZA, 2011, p. 10). Porém, o investimento na educação não foi suficiente para zelar pela qualidade dos serviços, com "aproximadamente, um terço do mínimo fixado pela constituição de 1946 e confirmada pela LDB de 1961. Descendo de $7,60 \%$ (em 1970), para 4,31\% (em 1975), recuperando-se um pouco em 1978, com 5,2\%” (SAVIANI, 2008, p. 299).

As mudanças estruturais demandaram um maior número de docentes, levando à criação de licenciaturas curtas, uma formação precária no ensino superior, e no ensino médio o curso de magistério foi considerado suficiente para lecionar no antigo primário, "configurando um quadro de precariedade bastante preocupante" (SAVIANI, 2009 , p. 147). No final do governo militar, o Brasil possuía uma realidade educacional que em nada se assemelhava àquela anterior a esse período, conforme explicam Ferreira e Bittar (2006, p. 1165):

\footnotetext{
Nessa época, o professorado brasileiro já não portava o perfil do passado, numericamente inferior e com origens nas camadas médias urbanas e nas próprias elites. Agora, em decorrência das mudanças estruturais do país e das reformas educacionais citadas, ele passava a ser uma categoria muito pouco assemelhada à anterior e submetida a condições de vida e de trabalho bastante diversas. Em síntese: o crescimento econômico acelerado do capitalismo brasileiro durante a ditadura militar impôs uma política educacional que se materializou, em linhas gerais, nas reformas de 1968 e 1971, cujos efeitos engendraram em parâmetros distintos dos anteriores.
}

É importante mencionar que desde os anos de 1960, Paulo Freire já tecia suas críticas ao modelo de educação neoliberal e sua ideologia fatalista, que busca frear o devir histórico ao realizar uma educação domesticadora, sob a qual a única importância é o de- 
senvolvimento da técnica necessária para ensinar, na esperança de que os educandos alcancem um bom emprego. Porém, foi no livro Pedagogia da Autonomia, publicado originalmente em 1996, que Freire (2008, p. 73) ampliou suas denúncias a essa concepção que busca formar o docente como "exercitador de destrezas". "Um educador com muito pouco de formador, com muito mais de treinador, de transferidor de saberes".

\begin{abstract}
Nos anos 60, preocupado já com esses obstáculos, apelei para a conscientização não como panaceia, mas como um esforço de conhecimento crítico dos obstáculos, vale dizer, de suas razões de ser. Contra toda a força do discurso fatalista neoliberal, pragmático e reacionário, insisto hoje, sem desvios idealistas, na necessidade da conscientização. Insisto na sua atualização (FREIRE, 2008, p. 28).
\end{abstract}

Ainda que Freire (2008) tenha realizado duras críticas à educação neoliberal, fazendo prognósticos certeiros sobre os baixos resultados que poderíamos com ela obter, o governo de Fernando Henrique Cardoso (1995-2002) tomou tais diretrizes como centrais em seu governo, alinhando a educação nacional às demandas dos órgãos neoliberais. Em um relatório chamado Education Sector Strategy, publicado pela OCDE, em 1999, no qual o direcionamento político do Chile é usado como exemplo a ser seguido pelas outras nações latino-americanas, o órgão aconselha aos países adotarem uma educação com conteúdos curriculares que desenvolvam competências e habilidades necessárias aos cidadãos, para que exerçam funções numa sociedade em constantes transformações tecnológicas e industriais (OCDE, 1999).

Vinculada às orientações dos órgãos neoliberais, as primeiras DCN para formação de Professores da Educação Básica, publicadas após a LDB de 1996, foram decretadas pela Resolução CNE/ CP $\mathrm{n}^{\circ} 1$, de 18 de fevereiro de 2002, e abrigou "a competência como concepção nuclear na orientação do curso" e "os conteúdos, como meio e suporte para a constituição das competências" (BRASIL, 2002, p. 9). Os Pareceres sobre os quais tal Resolução se sus- 
tenta apresentam pressupostos da psicologia do desenvolvimento de Jean Piaget, que foram transcritos para a educação por meio das metodologias de Philippe Perrenoud e Donald Schön.

Ao estudar os pressupostos presentes na teoria das competências, implementados pelas legislações brasileiras, Ramos (2001) encontrou uma mistura entre a psicologia do desenvolvimento de Jean Piaget e a teoria da competência linguística de Chomsky. Essa combinação de duas epistemologias, que aparentemente não se misturam, relacionou o desenvolvimento de competências a dispositivos biológicos e capacidades inatas, ou seja, competências são conhecimentos tácitos, que não devem ser desenvolvidos por aprendizagens, mas apenas por meio de vivências, causando confusão entre os educadores e educadoras sobre como utilizar os conteúdos programáticos para desenvolvê-las em seus alunos e alunas.

No início do século XXI, diversas pesquisas, como as de Pimenta (2002, 2005), Moretti (2007), Saviani (2009) e Ramos (2001, 2004), encontraram resultados próximos àqueles de Paulo Freire e afirmaram que as políticas públicas brasileiras deveriam "superar a noção de competências" (RAMOS, 2004, p. 47), pois essa epistemologia confunde personalidade com profissionalidade e busca formar um "indivíduo adaptável a uma realidade como sendo única possível. Nesse modelo educacional não há espaço para questionamento da primazia da competência individual, em prol de projetos políticos e práticas pedagógicas não alienantes" (MORETTI, 2007, p. 75). Conforme Moretti e Moura (2010, p. 352), "nessa concepção, falar em competências é falar em qualificações necessárias para atuar e adaptar-se a essa sociedade".

A partir de 2007, o Conselho Nacional de Educação (CNE) designou a "Comissão Bicameral de Formação de Professores, formada por conselheiros da Câmara de Educação Superior e da Câmara de Educação Básica, com a finalidade de desenvolver estudos e proposições sobre a temática” (BRASIL, 2015a, p. 1). Tal comissão foi desfeita e refeita com novos membros por diversas vezes, até que em 2015 apresentou o Parecer CNE/CP n 2, de 9 de junho de 2015, 
o qual afirmava a necessidade de "novas bases para a formação inicial e continuada de professores" (BRASIL, 2015a, p. 6) que busquem a descentralização da epistemologia das competências.

Após a publicação do Plano Nacional de Educação (PNE) 2014-2024, que apresentou audaciosas metas, como o investimento de $10 \%$ do PIB nacional para a educação, os quais dependiam dos royalties do Pré-sal (BRASIL, 2014, 2013), novas DCN para a formação de professores foram promulgadas pela Resolução $\mathrm{CNE} / \mathrm{CP} \mathrm{n}^{\circ}$ 2 , de $1^{\circ}$ de julho de 2015, a qual realiza o "reconhecimento da especificidade do trabalho docente, que conduz à práxis como expressão da articulação entre teoria e prática" (BRASIL, 2015b, p. 6) e amplia de três para quatro anos a duração mínima dos cursos de licenciaturas, entre outras mudanças. Ainda que a palavra competências não apareça no documento, o termo práxis também não é bem definido, embora o Parecer 02/2015 (BRASIL, 2015a) que fundamentou a Resolução (BRASIL, 2015b) apresente, ao longo do texto, a concepção de educação como processo emancipatório e permanente.

As DCN emitidas em 2015 deveriam ser implementadas pelos cursos de formação até julho de 2017, porém, esse prazo foi prorrogado por três vezes. A Resolução CNE/CP n ${ }^{\circ} 1$, de 9 de agosto de 2017 aumentou um ano no prazo (BRASIL, 2017), já a Resolução CNE/CP no 3, de 3 de outubro de 2018, ampliou mais um ano (BRASIL, 2018a) e a Resolução CNE/CP n n $^{\circ}$, de $1^{\circ}$ de julho de 2019, ampliou para mais seis meses, tendo como data final para implementação o dia de 22 de dezembro de 2019 (BRASIL, 2019a). Porém, antes mesmo de ter o seu último prazo de implementação encerrado, o governo federal emitiu novas DCN e revogou a Resolução no 2, de 2015.

As DCN emitidas em 2015 deveriam ser implementadas nos cursos de formação de professores até julho de 2017. Porém, antes do vencimento desse prazo, novas mudanças ocorreram no cenário político, com o impeachment da presidenta Dilma Rousseff, e prorrogações foram requeridas. É importante citar que as extensões no prazo ocorreram por pressões exercidas pelos representantes dos 
grupos financistas da educação, tal qual o conselheiro da educação Antônio Carbonari Netto, criador e financista do grupo Anhanguera, que no dia 3 de julho de 2018 realizou pedidos no MEC pela prorrogação dos prazos de implementação, e também por grupos de instituições federais, como a Associação Nacional dos Dirigentes das Instituições Federais de Ensino Superior (Andifes), que afirmou demandar mais tempo, pois as alterações necessárias para a Resolução no 2, de 2015, ainda não haviam sido plenamente efetivadas, pois deveriam ser "mais substanciais do que apenas o acréscimo na grade curricular” (BRASIL, 2018a, p. 2).

Quanto ao interesse dos grupos financistas, Diniz-Pereira (2007, p. 88) afirma que para os neoliberais, "programas de 'formação inicial' de quatro ou cinco anos seria algo muito caro e um 'luxo descabido' no caso das populações pobres e de cor [...]". A formação de três anos de bacharelado complementado por um ano de licenciatura já vinha sendo questionada durante muitos anos por pesquisadores do campo da formação docente, que defendiam cursos específicos de licenciatura em quatro anos, um avanço conquistado na Resolução CNE/CP 02/2015. Mas, conforme Pimenta e Lima (2019, p. 4), esses grupos empresariais que influenciam as políticas educacionais buscam pelo "aumento da eficiência de acordo com a fórmula: produzir mais, com menos gastos”, e querem que as DCN proponham cursos mais práticos do que teóricos, pois eles representam melhor o interesse do setor financeiro, que almeja professores/as que não questionem, não perguntem e apenas trabalhem com o sistema educativo desses próprios conglomerados que buscam o controle hegemônico do sistema educacional.

O grande crescimento numérico das IES privadas nessas duas primeiras décadas do século XXI coloca em evidência uma das principais crenças neoliberais. Para Hayek (1987), os serviços públicos não possuem qualidade por serem muito burocratizados e não estimularem a competição, porém, as IES privadas não vêm competindo com o aumento da qualidade, mas pela baixa mensalidade, a qual demanda um curso defasado, de baixa qualidade, e 
corpo docente com doutores insuficientes e pouca experiência, ficando muito aquém da qualidade das licenciaturas em IES pública. Conforme Diniz-Pereira (2015, p. 275), essas são “"universidades empresas' consideradas 'de massa', que têm como principal característica a cobrança de mensalidades mais baixas e um número muito grande de alunos".

Cabe ainda destacar que as faculdades privadas, que proliferam nos últimos anos para a formação docente, não têm a exigência da pesquisa. "A educação mercantilista promoveu a entrada de grandes empresas na educação superior, considerada um investimento lucrativo, sendo que a tríade ensino, pesquisa e extensão não é requisito para a formação docente, que se precariza" (CAMPOS, 2021, p. 2).

No interior dessa disputa de juízos, em que grupos buscam pela implementação hegemônica de suas concepções, no dia 20 de dezembro, de 2019, o CNE do atual governo, emitiu novas DCN para a formação de professores.

Revogando as Diretrizes de 2015, a nova diretriz instituída pela Resolução CNE/CP no 02/2019 (BRASIL, 2020) retoma a formação docente com ênfase no pragmatismo e desenvolvimento de competências, incluindo aquelas previstas na Base Nacional Comum Curricular - BNCC - para a educação básica.

A BNC-Formação realiza o retorno às orientações dos órgãos neoliberais e reintroduz a epistemologia das competências nos cursos de formação de professores e na educação básica. Uma epistemologia que, no bojo das disputas por diferentes projetos, nunca se foi por completo.

Várias entidades de classe na educação se manifestaram contra essa política, encaminhando ao Conselho Nacional de Educação um posicionamento conjunto das entidades acadêmico-científicas, entidades nacionais de dirigentes e trabalhadores de fóruns estaduais.

Os mais recentes movimentos e proposições do CNE rompem com a concepção e os princípios de base comum nacional para a educação básica e para a formação de professores edificada pelo movimento de educadores, desde os anos 1980, e materializada na Resolução CNE/CP n ${ }^{\circ}$ 
2/2015. Consideramos um grande retrocesso essa opção de retomar concepções ultrapassadas de formação restrita a habilidades e competências, como as expressas na BNCC (2017) e nas DCNs para a formação inicial (2019), agora para a formação continuada (ANFOPE et al., 2020, p. 1).

As novidades apresentadas pela BNC-Formação estão na necessidade sobre o desenvolvimento de uma base integrada de competências cognitivas e socioemocionais nos futuros professores e pela busca das metodologias com "evidências cientificas", pois, conforme a redação das DCN, essa "assegura que tais referenciais não fiquem reféns de 'achismos', mas expliquem como os estudantes aprendem determinados conteúdos em diferentes situações" (BRASIL, 2019b, p. 9). Essas duas novidades foram introduzidas como orientações do Banco Mundial, e dizem muito a respeito da diretividade dessas ações. Sobre as competências socioemocionais, destacamos os argumentos da ANPED (2019, p. 7):

\footnotetext{
Ora, pautar a formação em competências socioemocionais é inverter a lógica da profissão docente, a exemplo do que ocorre com a escola a partir das reformas neoliberais, em que seu papel altera-se com a adoção da BNCC e suas competências e habilidades, o mínimo, o essencial para atuar no mercado de trabalho e para ser a escola do acolhimento e da integração social, transforma o seu ethos. A inversão prevista, desconfigura a escola como espaço da mobilização de conhecimentos, de formação cultural e científica.
}

A busca por metodologias que se pautam em evidências científicas, conforme Christian Dunker (2021), também possui suas bases no pensamento neoliberal. Tem origem na medicina, nos anos de 1960, que, ao obter resultados satisfatórios na busca pela otimização dos recursos médicos para investimento na saúde, por meio de tomadas de decisões com base na maior evidência científica disponível, passou a ser utilizada em outros setores, como na psicologia e na educação, num esforço de padronizar e comparar as técnicas e abordagens.

Essas tentativas se dão por meio de publicações dos resultados das abordagens testadas em periódicos científicos, que avaliam 
a eficácia da intervenção, porém, de acordo com o psicanalista livre-docente da USP (DUNKER, 2021), mais de 40\% dos trabalhos realizados nessa metodologia não encontram confirmação quando as condições de objeto, método e produção experimental são reeditadas, visto que os padrões encontrados por essas intervenções costumam ser descritos como resultado comportamental de todos os seres humanos, mas diferentes do objeto e das intervenções da prática médica. As atividades que trabalham com indivíduos, em suas condições de sujeitos, são transformadas pelas particularidades dos sujeitos participantes de tais atividades.

Conforme Freire (2000, p. 54), "a natureza humana se constitui social e historicamente". Como sujeitos da consciência, não existem comportamentos humanos que prescindam a história, a cultura, a linguagem, ou seja, não há condutas que não estejam relacionadas ao trabalho acumulado de todas as gerações humanas que nos antecederam, de forma que os métodos baseados em evidências só reeditariam os mesmos resultados caso encontrassem dois sujeitos iguais, impossibilitando que os diversos sujeitos possam voltar-se criticamente sobre a realidade concreta condicionante.

Por isso, Freire (2001a, 2019) defende que o currículo parta dos saberes dos educandos a quem a metodologia educacional se destina, pois assim existe a possibilidade de, por meio do diálogo, não prescindir da realidade individual dos sujeitos, tampouco tornar-se uma realidade apriorística após a transformação, possibilitando a superação dos saberes de experiências, para saberes que se amparam em uma realidade social histórica e cultural, para, enfim, a vontade de ser sujeito e de ser mais. Sobre isso, Freire (1981, p. 54) assevera:

A possibilidade que têm os seres humanos de atuar sobre a realidade objetiva e de saber que atuam, de que resulta que a tornam como objeto de curiosidade, a sua comunicação mediatizada pela realidade, por meio de sua linguagem criadora, a pluralidade de respostas a um desafio singular, testemunham a criticidade que há nas relações entre eles e o mundo. Sua consciência, que não é fazedora arbitrária da objetividade, com a qual constitui uma unidade dialética, não é, também, por isso mesmo, uma pura cópia, um simples reflexo daquela. Daí que esta nota de criticidade não 
possa ser compreendida nem, de um lado, por quem absolutiza a objetividade, nem, de outro, por quem absolutiza a consciência. No primeiro caso, a consciência seria incapaz de voltar-se criticamente sobre a realidade concreta que a condiciona; no segundo, na medida em que fosse a criadora da realidade, seria um a priori desta. Em nenhuma das hipóteses nos parece viável compreender a ação transformadora dos seres humanos sobre o mundo. Do ponto de vista do objetivismo mecanicista, porque, mera réplica da realidade, a consciência seria objeto da realidade que, então, se transformaria a si mesma.

Por meio de uma leitura freireana, a BNC-Formação, quando utiliza uma epistemologia que busca o desenvolvimento de habilidades e de competências as quais se amparam no que o mercado de trabalho compreende hoje como sendo o professor ideal, busca formar um professor a-histórico, domesticador de alunos. Compreendidas como "ações antidialógicas", de caráter autoritário, inseridas no contexto de práticas bancárias, com "uma convicção quase inabalável de que lhes cabe 'transferir' ou 'levar', ou 'entregar' ao povo os seus conhecimentos, as suas técnicas. Veem-se, a si mesmos, como os promotores do povo" (FREIRE, 2019, p. 209).

Freire (2008) já havia alertado para o sequestro do termo autonomia realizado pelos neoliberais, os quais estimulam o individualismo e a competitividade, atribuindo aos sujeitos a responsabilidade por seus sucessos e fracassos. A BNC-Formação apresenta, em diversas passagens do documento, a intenção de formar professores capazes de desenvolver a autonomia dos educandos (BRASIL, 2020), abordando teoria e prática por meio do desenvolvimento de um rol de competências e habilidades, desconsiderando realidades diferentes, inviabilizando o desenvolvimento da autonomia, pois impede a formação para a construção da práxis. Trata-se de uma formação autoritária, que não permite a compreensão dos docentes sobre esse modelo diretivo, obstaculizando que assumam "uma ética a serviço das gentes, de sua vocação ontológica, a do ser mais e não de uma ética estreita e malvada, como a do lucro, a do mercado" (FREIRE, 2000, p. 46). 


\section{Considerações finais}

Refletir sobre formação docente, junto de Paulo Freire, demanda a compreensão que toda formação humana é permanente, pois os seres humanos são inconclusos, em busca de ser mais, transformando a realidade por meio da práxis. Porém, em realidades alienantes e domesticadoras, a liberdade e a autonomia do ser humano só se constrói com a compreensão crítica da realidade, para entender que as situações sociais, como hoje se dão, são construções históricas, realizadas pelo trabalho dos humanos e não apriorísticas, que existiriam independentemente dos sujeitos, como os fatalistas da história buscam descrevê-la. Com Paulo Freire, desenha-se um caminho de possibilidades para que os docentes compreendam a diretividade das ações educativas que se pretende impor no modelo formativo neoliberal, para que assim possam criticamente construir sua práxis.

Programas de formação docente para a domesticação, ou para a transformação, evidenciam o caráter iminentemente político da educação. Enquanto o modelo neoliberal abriga uma ideologia fatalista, que impossibilita a caminhada do ser humano para a autonomia, para ser mais, a pedagogia de Freire contribui para a compreensão dos condicionantes econômicos, políticos e sociais, possibilitando uma escolha ética nos cursos de formação de professores, em um processo de conscientização que evidencie o direcionamento do modelo hegemônico neoliberal.

Quanto mais se propõem políticas para a reforma dos cursos, com a publicação de novas DCN, mais fica claro que a solução não virá por esse caminho, como já havia afirmado Freire (2011). Inseridas em realidades repletas de polarizações políticas, as DCN para a formação de professores vêm sendo promulgadas pelos interesses de muitos conglomerados financistas, que estão diminuindo a qualidade da educação em benefício do maior lucro. As transformações que privilegiam o desenvolvimento da autonomia são construídas por meio da imersão crítica do sujeito em suas realidades, pela práxis.

O desafio é coletivo, por intermédio de análises críticas das políticas de formação no contexto da elaboração do Projeto 
Pedagógico de cada curso de licenciatura, com a participação das equipes de docentes universitários que formam os profissionais da educação básica.

Os fundamentos constantes na obra de Paulo Freire contribuem para que os professores dos cursos de licenciatura realizem essa escolha ética, a fim de que, por meio da problematização dos conteúdos e da criticização de seus educandos, transformem a realidade e a qualidade dos cursos, por meio de suas próprias práxis.

Os ataques a Paulo Freire vêm se intensificando, partindo especialmente do governo federal, que retoma o discurso falacioso de que educar é treinar. Esses ataques não são recentes e já foram respondidos pelo próprio Freire (2000, p. 52), quando afirmou que "Para mim, a briga pela atualização do sonho, da utopia da criticidade, da esperança é a briga pela recusa”.

É com sentimento de recusa e resistência que enfrentamos as políticas de domesticação que objetificam o sujeito, dificultando a superação das reais condições de opressão. Desmascarar o propósito enganador da formação para a autonomia apregoada pelo liberalismo conservador é nosso grande desafio.

\section{Referências}

ANDERSON, Perry. Balanço do Neoliberalismo in SADER, Emir; GENTILI, Pablo (orgs.). Pós-neoliberalismo: as políticas sociais e o Estado Democrático. Rio de Janeiro: Paz e Terra, 1995, p. 9-23). Disponível em: http://www.unirio. $\mathrm{br} /$ unirio/cchs/ess/Members/giselle.souza/politica-social-ii/texto-1-balanco-do-neoliberalismo-anderson. Acesso em 20 out. 2021.

ANFOPE et al. Posicionamento das entidades nacionais sobre o Parecer e a Minuta de Resolução do CNE que define as Diretrizes Curriculares Nacionais para a Formação Continuada de Professores da Educação Básica e institui a Base Nacional Comum para a Formação Continuada de Professores da Educação Básica (BNC-Formação Continuada), 2020. Disponível em: https://www.cedes.unicamp. br/dl/1jbjW\%2ADA0_MDA_bd0ac_. Acesso em: 14 ago. 2021.

ANPED. Uma formação formatada: posição da ANPED sobre o "texto referência - Diretrizes Curriculares Nacionais e Base Nacional Comum para a formação inicial e continuada de professores da educação básica". 2019. Disponível em: 
http://www.anped.org.br/news/posicao-da-anped-sobre-texto-referencia-dcn-e-bncc-para-formacao-inicial-e-continuada-de. Acesso em: 14 ago. 2021.

BRASIL. Conselho Nacional de Educação. Resolução CNE/CP nº $\mathbf{1}$, de 18 de fevereiro de 2002. Institui Diretrizes Curriculares Nacionais para a Formação de Professores da Educação Básica, em nível superior, curso de licenciatura, de graduação plena. 2002. Disponível em: http://portal.mec.gov.br/seesp/arquivos/ pdf/res1_2.pdf. Acesso em: 14 ago. 2021.

BRASIL. Lei $\mathbf{n}^{\circ}$ 13.005, de 25 de junho de 2014. Aprova o Plano Nacional de Educação (PNE) e dá outras providências. Brasília. Diário Oficial da República Federativa do Brasil, 26 jun. 2014. Disponível em: https://pne.mec.gov.br/. Acesso em 20 out. 2021.

BRASIL. Lei $\mathbf{n}^{\mathbf{0}} \mathbf{1 2 . 8 5 8}$, de 9 de setembro de 2013. Dispõe sobre a destinação para as áreas de educação e saúde de parcela da participação no resultado ou da compensação financeira pela exploração de petróleo e gás natural, com a finalidade de cumprimento da meta prevista no inciso VI do caput do art. 214 e no art. 196 da Constituição Federal; altera a Lei no 7.990, de 28 de dezembro de 1989; e dá outras providências. Brasília. Diário Oficial da União, 10 de setembro de 2013. Disponível em: http://portal.mec.gov.br/index.php?option=com docman\&view $=$ download\&alias $=14017-$ lei-12858\&category slug=setembro-2013-pdf\&Itemid $=30192$. Acesso em 20 out. 2021.

BRASIL. Conselho Nacional de Educação. Parecer $\mathrm{CNE} / \mathrm{CP} \mathbf{n}^{\mathbf{0}}$ 2, de 9 de junho de 2015.

Diretrizes Curriculares Nacionais para a Formação Inicial e Continuada dos Profissionais do Magistério da Educação Básica. Brasília: Diário Oficial da União, Seção 1, p. 13, 2015a. Disponível em: http://pronacampo.mec.gov.br/images/pdf/ parecer_cne_cp_2_2015_aprovado_9_junho_2015.pdf. Acesso em: 10 ago. 2021.

BRASIL. Conselho Nacional de Educação. Resolução CNE/CP n ${ }^{\circ}$ 2/2015, de $1^{\circ}$ de julho de 2015. 2015b. Define as Diretrizes Curriculares Nacionais para a formação inicial em nível superior (cursos de licenciatura, cursos de formação pedagógica para graduados e cursos de segunda licenciatura) e para a formação continuada. Brasília: Diário Oficial da União, Seção 1, p. 8-12, 2 jul. 2015. Disponível em: http://pronacampo.mec.gov.br/images/pdf/res_cne_cp_02_03072015. pdf. Acesso em: 10 ago. 2021.

BRASIL. Conselho Nacional de Educação. Resolução CNE/CP n ${ }^{0}$ 1/2017, de 9 de agosto de 2017. Altera o Art. 22 da Resolução CNE/CP n ${ }^{\circ}$ 2, de $1^{\circ}$ de 2015, que define as Diretrizes Curriculares Nacionais para a formação inicial em nível superior (cursos de licenciatura, cursos de formação pedagógica para graduados 
e cursos de segunda licenciatura) e para a formação continuada. Brasília: Diário Oficial da União, Seção 1, p. 26, 2017. Disponível em: http://portal.mec.gov.br/ docman/agosto-2017-pdf/70141-rcp001-17-pdf/file. Acesso em: 20 ago. 2021.

BRASIL. Conselho Nacional de Educação. Parecer CNE/CP n ${ }^{0}$ 7/2018, de 3 de julho de 2018. Solicitação de prorrogação do prazo estabelecido na Resolução $\mathrm{CNE} / \mathrm{CP} \mathrm{n}^{\circ}$ 1, de 9 de agosto de 2017, que alterou o artigo 22 da Resolução $\mathrm{CNE} / \mathrm{CP} \mathrm{n}^{\circ} 2$, de $1^{\circ}$ de julho de 2015. Aprovado em 3 jul. 2018. Brasília: Diário Oficial da União, Seção 1, p. 18, 2018a. Disponível em: http://portal.mec.gov.br/ index.php?option $=$ com_docman\&view $=$ download\&alias $=90811-$ pcp007-18\&category_slug=julho-2018-pdf\&Itemid=30192. Acesso em: 20 ago. 2021.

BRASIL. Conselho Nacional de Educação. Resolução CNE/CP n ${ }^{\circ} \mathbf{3} / \mathbf{2 0 1 8}$, de 3 de outubro de 2018. Altera o Art. 22 da Resolução CNE/CP nº 2, de $1^{\circ}$ de 2015, que define as Diretrizes Curriculares Nacionais para a formação inicial em nível superior (cursos de licenciatura, cursos de formação pedagógica para graduados e cursos de segunda licenciatura) e para a formação continuada. Brasília: Diário Oficial da União, Seção 1, p. 21, 2018b. Disponível em: http://portal.mec.gov.br/ index.php?option $=$ com_docman\&view $=$ download $\&$ alias $=98131-$ rcp003-18\&category_slug=outubro-2018-pdf-1\&Itemid=30192. Acesso em: 20 ago. 2021.

BRASIL. Conselho Nacional de Educação. Resolução CNE/CP n ${ }^{\circ}$ 1/2019, de 2 de julho de 2019. Altera o Art. 22 da Resolução $\mathrm{CNE} / \mathrm{CP} \mathrm{n}^{\circ} 2$, de $1^{\circ}$ de julho de 2015, que define as Diretrizes Curriculares Nacionais para a formação inicial em nível superior (cursos de licenciatura, cursos de formação pedagógica para graduados e cursos de segunda licenciatura) e para a formação continuada. Brasília: Diário Oficial da União, Seção 1, p. 35, 2019a. Disponível em: http://portal.mec. gov.br/index.php?option $=$ com_docman\&view $=$ download \&alias $=116731-$ rcp001-19\&category_slug=julho-2019-pdf\&Itemid=30192. Acesso em: 20 ago. 2021.

BRASIL. Conselho Nacional de Educação/Conselho Pleno. Parecer CNE/CP $\mathbf{n}^{\circ}$ 22/2019, de 7 de novembro de 2019. 2019b. Diretrizes Curriculares Nacionais para a Formação Inicial de Professores para a Educação Básica e Base Nacional Comum para a Formação Inicial de Professores da Educação Básica (BNC-Formação). Brasília: Diário Oficial da União, Seção 1, p. 142, 20 dez. 2019. Disponível em: https://www.cenpec.org.br/wp-content/uploads/2020/01/pcp022_19.pdf. Acesso em: 20 ago. 2021.

BRASIL. Conselho Nacional de Educação/Conselho Pleno (CNE/CP). Resolução CNE/CP n ${ }^{\circ}$ 2, de 20 de dezembro de 2019. Define as Diretrizes Curriculares Nacionais para a Formação Inicial de Professores para a Educação Básica e institui a Base Nacional Comum para a Formação Inicial de Professores da Educação Básica (BNC-Formação). Brasília: Diário Oficial da União, Seção 1, 15 abr. 2020. Disponível em: http://portal.mec.gov.br/index.php?option=com_do- 
cman\&view=download\&alias=135951-rcp002-19\&category_slug=dezembro-2019-pdf\&Itemid=30192. Acesso em: 14 ago. 2021.

CAMPOS, Elisabete F. Esteves. Diretrizes curriculares para a formação de professores: a práxis freiriana em perspectiva. Olhar de Professor, Ponta Grossa, v. 24, p. 1-19, 2021. Disponível em:

https://revistas2.uepg.br/index.php/olhardeprofessor/article/ view/16760/209209214213. Acesso em: 8 ago. 2021.

DINIZ-PEREIRA, Júlio Emílio. Formação de professores, trabalho docente e suas repercussões na escola e na sala de aula. Educação \& Linguagem, ano 10, n. 15, p. 82-98, jan./jun. 2007. Disponível em: https://www.metodista.br/ revistas/revistas-metodista/index.php/EL/article/view/158. Acesso em: 20 ago. 2021.

DINIZ-PEREIRA, Júlio Emílio. A situação atual dos cursos de licenciatura no Brasil frente à hegemonia da educação mercantil empresarial. Revista Eletrônica de Educação, v. 9, n. 3, p. 273-280, 2015. Disponível em: http://www.reveduc. ufscar.br/index.php/reveduc/article/view/1355. Acesso em: 10 ago. 2021.

DUNKER, Christian. Psicanálise baseada em evidências. 2021. 1 vídeo (22 min.). Disponível em: https://www.youtube.com/watch?v=CZe1Y-4VunA. Acesso em: 26 ago. 2021.

FERREIRA, Amarílio; BITTAR, Marisa. A ditadura militar e a proletarização dos professores. Cadernos Cedes, Campinas, v. 27, n. 97, p. 1159-1179, set./ dez. 2006.

FREIRE, Paulo. Ação cultural para a liberdade: e outros escritos. 5. ed. São Paulo: Paz e Terra, 1981.

FREIRE, Paulo. Pedagogia da esperança: um reencontro com a pedagogia do oprimido. São Paulo: Paz e Terra, 1997.

FREIRE, Paulo. Pedagogia da indignação: cartas pedagógicas e outros escritos. São Paulo: Unesp, 2000.

FREIRE, Paulo. Educação na cidade. São Paulo: Cortez Editora, 2001a.

FREIRE, Paulo. Política e educação. 5. ed. São Paulo: Afiliada, 2001 b. 
FREIRE, Paulo. Pedagogia da autonomia: saberes necessários à prática educativa. 37. ed. São Paulo: Paz e Terra, 2008.

FREIRE, Paulo. Educação como prática de liberdade. São Paulo: Paz e Terra, 2011.

FREIRE, Paulo. Pedagogia do oprimido. 67. ed. São Paulo: Paz e Terra, 2019.

FREITAS, Luiz Carlos de. Os reformadores empresariais da educação: da desmoralização do magistério à destruição do sistema público de educação. Educação \& Sociedade, Campinas, v. 33, n. 119, p. 379-404, abr./jun. 2012. Disponível em: https://www.scielo.br/j/es/a/PMP4Lw4BRRX4k8q9W7xKxVy/?format=pdf\&lang=pt. Acesso em: 10 abr. 2021.

FREITAS, Luiz Carlos de. A reforma empresarial da educação: nova direita, velhas ideias. São Paulo: Expressão Popular, 2018. Disponível em: https://www.expressaopopular.com.br/loja/wp-content/uploads/2020/05/ Reforma-Empresarial-da-Educa $\% \mathrm{C} 3 \% \mathrm{~A} 7 \% \mathrm{C} 3 \% \mathrm{~A} 30 . \mathrm{pdf}$. Acesso em: $10 \mathrm{abr}$. 2021.

GADOTTI, Moacir. "Prefácio. Vigência das ideias de Freire”. In: PELANDRÉ, Nilcéia Lemos. Ensinar e aprender com Paulo Freire: 40 horas, 40 anos depois. São Paulo, Florianópolis: Cortez Editora, Instituto Paulo Freire, Editora da UFSC, 2002 .

GIROUX, Henry. Trump's neo-nazis and the rise of illiberal democracy. 2017. Disponível em: https://truthout.org/articles/neo-nazis-in-charlottesville-and-the-rise-of-illiberal-democracy/. Acesso em: 10 abr. 2021.

HAYEK, Friedrich. O caminho da servidão. Rio de Janeiro: Expressão e Cultura, 1987.

KUENZER, Acácia Zeneida. Ensino médio e profissional: as políticas do estado neoliberal. São Paulo: Cortez Editora, 1997.

LARAIA, Roque de Barros. Cultura: um conceito antropológico. 14. ed. Rio de Janeiro: Zahar, 2001.

MORETTI, Vanessa Dias. Professores de matemática em atividade de ensino: uma perspectiva histórico-cultural para a formação docente. 2007. 207 f. Tese (Doutorado em Educação) - Faculdade de Educação, Universidade de São Paulo, São Paulo, 2007. 
MORETTI, Vanessa Dias; MOURA, Manoel Oriosvaldo de. A formação docente na perspectiva histórico-cultural: em busca da superação da competência individual. Psicologia Política, v. 10, n. 20, p. 345-361, jul./dez., 2010.

OCDE. Education Sector Strategy, 1999. Disponível em: https://documents.worldbank.org/en/publication/documents-reports/documentdetail/406991468178765170/education-sector-strategy. Acesso em: 14 ago. 2021.

RAMOS, Marise Nogueira. A pedagogia das competências: autonomia ou adaptação? São Paulo: Cortez Editora, 2001.

RAMOS, Marise Nogueira. O projeto unitário de ensino médio sob os princípios do trabalho, da ciência e da cultura. In: FRIGOTTO, G.; CIVATTA, M. (org.). Ensino médio: ciência, cultura e trabalho. Brasília: MEC/SEMTEC, 2004. p. 31-52.

PIMENTA, Selma Garrido. O estágio na formação de professores: unidade, teoria e Prática? 5. ed. São Paulo: Cortez Editora, 2002.

PIMENTA, Selma Garrido. Professor reflexivo no Brasil: gênese e crítica de um conceito. 2. ed. São Paulo: Cortez Editora, 2005.

PIMENTA, Selma Garrido; LIMA, Maria Socorro Lucena. Estágios supervisionados e o Programa Institucional de Bolsa de Iniciação à Docência: duas faces da mesma moeda? Revista Brasileira de Educação, v. 24, 2019. Disponível em: http://www.scielo.br/pdf/rbedu/v24/1809-449X-rbedu-24-e240001.pdf. Acesso em: 20 set. 2021.

SAVIANI, Dermeval. O legado educacional do Regime Militar. Cadernos Cedes, Campinas, v. 28, n. 76, p. 291-312, set./dez. 2008. Disponível em: https://doi. org/10.1590/S0101-32622008000300002. Acesso em: 5 out. 2021.

SAVIANI, Dermeval. Formação de professores: aspectos históricos e teóricos do problema no contexto brasileiro. Revista Brasileira de Educação, v. 14, n. 40, jan./abr. 2009. Disponível em: https://doi.org/10.1590/S141324782009000100012. Acesso em: 5 out. 2021.

SOUZA, Roger Marchesini. Fracasso escolar, a construção de um tema. Revista Múltiplas Leituras, v. 4, n. 1, p. 53-69, 2011. Disponível em: https://www.metodista.br/revistas/revistas-ims/index.php/ML/article/view/2567. Acesso em: 5 out. 2021. 